Georgia State University

ScholarWorks @ Georgia State University

$7-2020$

\title{
What is the role of emotions in educational leaders' decision making? Proposing an organizing framework
}

Yinying Wang

Georgia State University, ywang103@gsu.edu

Follow this and additional works at: https://scholarworks.gsu.edu/eps_facpub

Part of the Education Commons, and the Education Policy Commons

\section{Recommended Citation}

Wang, Yinying, "What is the role of emotions in educational leaders' decision making? Proposing an organizing framework" (2020). Educational Policy Studies Faculty Publications. 41.

https://scholarworks.gsu.edu/eps_facpub/41

This Article is brought to you for free and open access by the Department of Educational Policy Studies at ScholarWorks @ Georgia State University. It has been accepted for inclusion in Educational Policy Studies Faculty Publications by an authorized administrator of ScholarWorks @ Georgia State University. For more information, please contact scholarworks@gsu.edu. 
What Is the Role of Emotions in Educational Leaders' Decision Making?

Proposing an Organizing Framework

$$
\text { Yinying Wang* }
$$

Georgia State University

Yinying Wang is an assistant professor of Educational Leadership in the Department of Educational Policy Studies at College of Education and Human Development in Georgia State University. Her research interest intersects technology, neuroscience, social network analysis in educational leadership and policy, and leaders' decision making.

* Correspondence concerning this manuscript should be addressed to:

Yinying Wang

Georgia State University, 30 Pryor Street, Room 420, Atlanta, GA 30302-3977

Email: ywang103@gsu.edu 
What Is the Role of Emotions in Educational Leaders' Decision Making?

\section{Proposing an Organizing Framework}

Decision making - choosing a course of action from a set of options - lies at the heart of leadership. The decisions made by educational leaders are overtly manifested by their behaviors (Sergiovanni, 1992). Prior literature on educational leadership examined decision making through broad brush strokes, such as making decisions through data-driven, shared, and contingent approaches (Tarter \& Hoy, 1998). These decision-making approaches, albeit valuable, do not explain the process of how a decision is made exactly. For instance, data-driven decisionmaking approach entails enormous cognitive capacity, as leaders collect, analyze, and interpret data. This decision-making approach tacitly leaves out emotions, probably assuming either emotions are irrelevant in a leader's decision making, or emotions work against optimal decision making. Yet such tacit assumptions have been confronted by a wealth of empirical evidence from multiple disciplines, including psychology—one of educational leadership's neighboring fields (Wang \& Bowers, 2016), behavioral economics - the field in which psychologists and economists study decision making and the resultant human behavior, and neuroeconomics—-the field intersecting behavioral economics and cognitive neuroscience that focuses on brain mechanisms of decision making (Glimcher \& Fehr, 2014). The convergent findings from these multiple disciplines indicate that emotions play a pervasive, predictable, sometimes deleterious but other times instrumental role in decision making (Lerner, Li, Valdesolo, \& Kassam, 2015). If emotions do not necessarily cloud leaders' decision making, then what and when do emotions promote or impede educational leaders' optimal decision making? This article thus aims to investigate the role of emotions in educational leaders' decision making by synthesizing the literature intersecting emotions, decision making, and organizational behavior from multiple 
disciplines (administrative science, psychology, behavioral economics, cognitive neuroscience, and neuroeconomics).

Grounded in multidisciplinary literature, this conceptual article proposes an organizing framework of educational leaders' emotions in decision making. The framework, as illustrated in Figure 1, includes four core propositions: (1) decisions are the outcomes of the interactions between emotions and cognition; (2) at the moment of decision making, emotions have a pervasive, predictable impact on decision making; (3) before making decisions, leaders' individual differences (e.g., trait affect and power) and organizational contexts (e.g., organizational justice and emotional contagion) have a bearing on leaders' emotions and decision making; and (4) post-decision behavioral responses trigger more emotions (e.g., regret, guilt, and shame) which, in turn, influence the next cycle of decision-making process. Proposition 1 (the emotion-cognition interactions) serves as the foundational proposition, undergirding the other three propositions that describe the role of emotions prior to, at the moment of, and after decision making.

\section{[Insert Figure 1]}

The proposed organizing framework is important on both theoretical and practical fronts. Theoretically, an enriched understanding of emotions and decision making brings conceptual cohesion to the field of educational leadership. The conceptual groundings in our field have been considered by many scholars as fragmented (Hoy, 1982; Wang, 2018), lacking a "coherent conceptual unity" (Oplatka, 2009, p. 15). What, if anything, can conceptually unify the field of educational leadership? To date, many dominant theoretical constructs in educational leadership have been centering around behavior, ranging from leadership behavior to organizational behavior (Wang, 2019). In fact, prior to these visible behaviors, there are decisions sent from 
human brains to muscles which execute the decisions through behaviors. To that end, the mostly invisible mental process that generates a decision has great potential to bring conceptual cohesion to the field, if we conceptualize the visible leadership behaviors from the lens of invisible, underlying decision-making processes. In addition to the theoretical significance, this article offers practical guidance to educational leadership practitioners in terms of identifying their own emotions and the emotions of others, and then regulating the emotions to make wise decisions. Decision making is the very foundation of leadership, including both leaders' individual decision making and how leaders ensure that their teams make wise decisions collectively as a group. The predictable effect of emotions on decision making is particularly practical for the leaders as they reflect on and optimize their decision making.

In the following pages, given emotions as one of the underexplored dimensions in educational leaders' decision making (Berkovich \& Ori, 2015), I begin with defining emotions, followed by taking stock of the extant literature on emotions in educational leadership. This knowledge base sets the stage for integrating the existing educational leadership literature into the literature on emotions and decision making in order to develop an organizing framework of educational leaders' emotions in decision making. Here I proceed to define emotions.

\section{What is an Emotion?}

Before we define emotions, it would be helpful if we survey the progress that has been made in our understanding of emotions. Plato viewed emotions — such as passion, desire, and fear-as destructive, insolent horses pulling people away from reasoning (Cooper \& Hutchinson, 1997). Adam Smith disagreed. In his book The Theory of Moral Sentiments, Adam Smith (1759/1976) underscored the importance of sentiments in moral decision making. Ekman and Friesen (1971) identified that six emotions — anger, fear, disgust, surprise, sadness, and 
happiness - were universal among humans, regardless of cultural backgrounds. However, the theory of constructed emotion posited that human emotions were not universal, but socially constructed (Barrett, 2017). We are not all the same. Some may experience awe, excitement, and hope while listening to a charismatic leader's speech; others may have no emotional response at all (Molenberghs, Prochilo, Steffens, Zacher, \& Haslam, 2017). This is because emotions emerge from billions of neurons (i.e., brain cells) that wire themselves as we navigate in and adapt to the environment. Different experiences (e.g., upbringings, cultural backgrounds, and daily encounters) create different connections among neurons which bring about different emotions.

On the neuroscience front, in the 1950s, the limbic system — a certain set of brain areaswas considered as the brain structure from which emotions emerged, but was not involved in cognition (MacLean, 1954). The concept of the limbic system as the emotional brain has been so influential that many current neuroscience textbooks still routinely include a chapter of the limbic system. While MacLean's limbic system theory of emotion was not completely wrong, evidence began to dispute some of its claims. For example, the hippocampus, the centerpiece in MacLean's proposed limbic system, was found to have both emotional and cognitive functions (Bechara, Tranel, Damasio, Adolphs, Rockland, \& Damasio, 1995). The current view is that multiple brain areas constitute a distributed system in our brain: a thought or an emotion does not occur in one brain area, but involve multiple brain areas (Gazzaniga et al., 2013).

What is an emotion exactly? To define emotions is like to wade through murky waters with a set of overlapping concepts (e.g., feeling, mood, and affect). To understand emotions, let us start with feelings. In our daily conversations, emotions and feelings are used interchangeably. In scholarly literature, however, there is a distinction between emotions and feelings. Feelings "are mental experiences that accompany a change in body state" (Damasio \& Carvalho, 2013, p. 
144). Feelings can be triggered by both internal and external stimuli. When our brains do not have sufficient blood flow, we feel dizzy. Feelings can also be triggered by external stimuli, such as social interactions. As the saying goes, "Words are said. Feelings are hurt." Emotions, on the other hand, are largely triggered by external stimuli (e.g., sight, hearing, touch, taste, and smell). In emotion research, subjective feelings are only one component of emotions. In addition to the subjective feelings, emotions have two other components: physiological responses (e.g., spiking blood pressure or sweating palms) and behavioral responses (e.g., avert others' eyes when we feel guilty or fret when we feel anxious; Gazzaniga, Ivry, \& Mangun, 2013).

A term related to emotions is mood: "a relatively lasting state that is predominantly defined by subjective feelings that may or may not be linked to a specific event" (Glimcher \& Fehr, 2014, p. 220). An even broader term is affect, which is an overarching term of the constructs, including emotions, mood, and emotion-related traits (Lerner et al., 2015). Affect is further distinguished between state affect and trait affect. State affect refers to the experience of positive (i.e., state positive affect, such as feeling enthusiastic and energetic) or negative feelings (i.e., state negative affect, such as anger and anxiety; Watson \& Clark, 1984). In addition to state affect, some people are prone to experience positive emotions consistently across time and situations (e.g., glass is always half full), thereby having the trait positive affect. By contrast, those who have a penchant for experiencing negative feelings and have a negative self- and worldview are considered to have the trait negative affect (e.g., glass is always half empty).

Human emotions are aroused faster than the activation of cognitive system in brains. Human brains generate and process emotions within one-tenth of a second (100 milliseconds), faster than the activation of cognitive system which takes more than 180 milliseconds (Decety \& Cacioppo, 2012). We feel before we think. Our emotions usually rush ahead before our brains 
process evidence and data to reach a decision. The emotion-laden, gut-feeling decision-making process is fast and subconscious, enabling us to make decisions without an extensive search for information, evidence, or data. More intriguingly, when we are asked to explain our decisions, our brains generate post hoc explanations which "are all based on what makes it into our consciousness, but the reality is the actions and the feelings happen before we are consciously aware of them — and most of them are the results of nonconscious processes, which will never make it into the explanations" (Gazzaniga, 2011, p. 77-78).

Emotions, therefore, are a mental shortcut that allows people to make decisions efficiently (Finucane, Alhakami, Slovic, \& Johnson, 2000). Using such a mental shortcut, leaders' decisions are rarely rational, even though leaders may claim their decisions are rational because it is socially desirable to do so (Fineman, 2003). Describing how moral decisions are made, psychologist Jonathan Haidt used the elephant-rider analogy: the emotion-laden process is the elephant; the cognitive-driven process is the rider (Haidt, 2012). Since the metaphorical elephant is activated faster than the rider, the rider's (our conscious reasoning) job is to serve the elephant (emotional responses): sometimes the rider reins in emotions when they run wild, other times the rider provides a post hoc rationalization. Sometimes the emotion-laden decisionmaking process serves us well, such as helping others without a prolonged deliberative cost-andbenefit analysis; other times it gets us into trouble, such as implicit racial bias, a point I will return to shortly. Before venturing into the inner workings of emotions in decision making, I first put emotions in the context of educational leadership literature to elucidate where emotions stand in the field of educational leadership. 


\section{Emotions and Educational Leadership}

Emotions play an integral role in educational leadership (James, Crawford, \& Oplatka, 2018). In a recently proposed affective paradigm for educational leadership theory and practice, emotions take a central role to connect leadership practices, influence, and power. Considering educational leadership as a social process in which leaders influence others' motivation, perceptions, and practices to advance teaching and learning, the integral role of emotions in educational leadership stems from the social functions of emotions in communication and motivation (Keltner \& Haidt, 1999).

First, emotions have a communication function (Barrett, 2017). We broadcast our emotional experience to our social partners. The facial expressions, caused by 42 small muscles on each side of our face, provide the information on our emotional status and perceptions of relationship with our social partners (Ekman, 1993). Moreover, many emotions (e.g., empathy, compassion, love, guilt, envy, and schadenfreude) are viewed as social emotions, because they only make sense in social settings (Keltner \& Haidt, 1999). Our emotions can be triggered by an array of social stimuli, including people's facial expressions, the words uttered by others, and the memory of our interactions with others (Gazzaniga et al., 2013). Further, we unconsciously mimic the facial expressions of our social partners with whom we interact, thereby increasing our emotional bond. As a result, emotions are considered to be inherently social, helping people “navigate and coordinate social interactions by providing information about others' motives and dispositions, ultimately allowing for the creation and maintenance of healthy and productive social relationships" (Lerner et al., 2015, p. 810). In a recent review of 49 empirical articles of emotions and educational leaders, Berkovich and Ori (2015) asserted that educational leaders' emotional experiences and emotion expressions indicated their reactions to the surrounding 
social reality. As such, it is no surprise that the literature on social justice leadership is peppered with references to emotions: the emotional toll taken by social justice-driven leaders (Theoharis, 2007), the palpable fear felt by undocumented students and their families (Figueroa, 2017), and anger and angst expressed by some high-performing students' parents whose resources were taken away to support low-performing students (Zirkel \& Pollack, 2016).

In addition to the communication function, emotions have a motivational function. The root of the word $e$-motion suggests that emotions compel us to act (Johnston \& Olson, 2015). More important, different emotions motivate our behaviors differently, such as anger motivating us to be aggressive, fear motivating us to flee, and gratitude motivating us to help others (Lerner et al., 2015). The examples in education include that anger over budget cut prompted teachers to protest (Waldron, 2019), and guilt prompted teachers to advocate for their students in urban schools (Mawhinney \& Rinke, 2017). Further, invigorating emotional arousal is one of the sources of self-efficacy (Bandura, 1997). Teachers' self-efficacy_partly derived from emotional arousal — was found to be a salient motivational factor for professional learning and teaching practices (Thoonen, Sleegers, Oort, Peetsma, \& Geijsel, 2011). By contrast, teachers felt demotivated and emotionally exhausted, when they lacked the emotional bond with their leaders, when they felt that their relationship with the leader was transactional rather than transformational, and when the leaders implemented accountability policies abrasively without considering teachers' emotions (Leithwood, Steinbach, \& Jantzi, 2002; Schwab \& Iwanicki, 1982). School leaders' emotional framing was found to be a mediator of the relationship between the leaders' transformational leadership and teachers' motivation (Berkovich \& Ori, 2017).

The social functions of emotions in communication and motivation undergird the integral role of emotions in educational leadership. Many of the dominant theoretical constructs (e.g., 
transformational leadership, motivation, self-efficacy, trust, and organizational citizenship behavior) in educational leadership have an emotional component (Wang, 2019). Considering the observable leadership behavior as the overt manifestation of decision making (Sergiovanni, 1992), one might ask: What is the role of emotions in leaders' decision making? Lakomski and Evers (2010) asserted the essential role of emotions in educational leaders' decision making. Yet, little research has addressed how different emotions influence decision making. If emotions, as argued by Lerner et al. (2015), have a pervasive, predictable, sometimes deleterious but other times instrumental impact on decision making, then what and when do emotions promote or impede educational leaders' optimal decision making? Grounded in multidisciplinary literature on emotions and decision making, this article thus proposes an organizing framework to synthesize the role of emotions in educational leaders' decision making.

\section{The Organizing Framework}

The organizing framework of educational leaders' emotions in decision making (see Figure 1) has four core propositions: (1) decisions are the outcomes of the interactions between emotions and cognition; (2) at the moment of decision making, emotions have a pervasive, predictable impact on decision making; (3) before making decisions, leaders' individual differences and organizational contexts have a bearing on leaders' emotions and decision making; and (4) post-decision behavioral responses trigger more emotions which, in turn, influence the next cycle of decision-making process. Here I elucidate each of the propositions with the evidence uncovered in multiple disciplines.

\section{Proposition 1: Decisions are the outcomes of emotion-cognition interactions.}

Emotions and cognition work together to generate a decision. First, emotions narrow or broaden the scope of human attention, thereby influencing information input into the cognitive 
system in human brains. Emotionally salient stimuli (e.g., an armed intruder threatening students and teachers in a school building) demand our attention, allowing the cognitive system to focus selectively on central details of the environment while ignoring or devoting fewer cognitive resources to peripheral details (Öhman, 2005). Some emotions (e.g., fear and pride) narrow the breadth of attention, so decision makers stick to an option about which they know more, rather than searching for options about which they have less information, such as seeking and taking other's advice (Gino \& Schweitzer, 2008). By contrast, other emotions (e.g., gratitude and shame) broaden people's attention breadth, enabling them to broadly explore options through advice-seeking behavior (Fredrickson \& Branigan, 2005).

Second, in human brains, the emotional system and the cognitive system are so intertwined in decision-making processes that there is no emotion-cognition dichotomy (Damasio, 1994). According to neuroscience literature, there are two stages in the neural mechanism of decision making: the valuation stage and the choice stage (see Supplement for a detailed discussion of brain mechanisms of decision making). At the valuation stage, human brains produce a subjective value of each option in a choice set. To do so, our brains integrate various components of each option into a single measure of subjective value (Kable \& Glimcher, 2009). The subjective value of each option is encoded by many components, including reward (e.g., What and how much reward does the option offer?), probability (e.g., How likely is it to attain the reward? How much risk am I willing to take?), effort and cost (e.g., How much effort does it take to attain the reward? How long am I willing to wait for the reward?), contexts (e.g., sleep deprivation, time constraint, and psychological stress), and preferences (Gazzaniga et al., 2013). Almost every human decision involves at least one of three preferences: risk preference (preference for risk aversion or risk seeking), social preference (preference for benefiting or 
disregarding others), and time preference (preference for a smaller immediate reward here and now or a larger delayed reward there and later). The brain networks (i.e., a set of brain areas) that are activated at the option valuation of risk, social, and time preferences are the ones that process both emotions and cognition. Therefore, there is no unique brain network that processes emotions exclusively. From the perspective of brain structures and functions, emotions cannot be separated from cognition, and vice versa. More important, emotions play a predictable role at this valuation stage, as I describe in detail in Proposition 2. Following the valuation stage in which the subjective values of options are generated, the choice stage occurs. At the choice stage, decision-makers' brain selects the most valued option, takes a winner-take-all approach, and sends motor commands to muscles to execute the decision through behavioral responses.

Given the brain mechanisms of decision making, people make decisions not only by cognitively evaluating the choice options, but also by gut feelings and emotions (Bechara, 2004). Pfister and Böhm (2008) further articulated four roles of emotions in decision making: (1) emotions, in the form of physiological arousal (e.g., the variation in heart rate and sweating), provide information about pleasure and pain for preference construction and option valuation; (2) emotions enable rapid choices and thus efficient decision making under time pressure; (3) emotions focus decision-makers' attention on relevant aspects of a decision; and (4) emotions, particularly social emotions, hold sway over people's social preference in option valuation, and thus influence decisions in social settings. That is, both emotions and cognition guide our decision making and the resultant behavior; thus, emotions should not be simply dismissed as a disrupting force that cloud educational leaders' decision making. 


\section{Proposition 2: Emotions have a pervasive, predictable role at the moment of decision making.}

Emotions have a pervasive, predictable role at the moment of decision making. The decisions are influenced not only by the emotions aroused by the decisions at hand (i.e., integral emotions), but also by the emotions that are unrelated to decisions (i.e., incidental emotions). Further, not all emotions influence decision making in the same way: anger makes us aggressive and impulsive, but fear makes us flee from danger and threat. Even the same emotion of empathy could lead us to make moral decisions in some contexts, but immoral decisions in others. Here I discuss in detail the predictable effect of emotions on the three preferences involved in almost every human decision: risk, social, and time preferences.

Risk preference. Educational leaders, like all humans, rarely make decisions with full knowledge of each option's consequences. In the face of uncertainty, risk becomes one component in leaders' option valuation over the decision-making processes. One tenet of rational choice theory is that people's selections from available options are consistent, regardless of how risks are framed in options (Sheffer, Loewen, Soroka, Walgrave, \& Sheafer, 2017). However, when making decisions under risk, people tend to be risk-seeking when they believe they face potential losses, but risk-averse when they believe they face potential gains, even when the options remain the same (Kahneman \& Tversky, 1979). Whether an option is framed as a loss or gain is associated with the brain activity in an emotion-processing brain area called the amygdala, suggesting a key role of emotions in people's risk preferences (De Martino, Kumaran, Seymour, \& Dolan, 2006). Generally, positive emotions function like rose-tinted spectacles. People with positive emotions (e.g., optimism, excitement, and happiness) are more likely to identify opportunities than threats, are more courageous than timid, and are more willing to takes 
risks (Mittal \& Ross, 1998). Positive emotions thus embolden leaders to select a risky option that would otherwise be considered overly risky.

On the other hand, negative emotions' effect on risk preference is more complicated. For instance, anger increases risk-taking in men; whereas disgust decreases risk-taking in women (Fessler, Pillsworth, \& Flamson, 2004). Further, anger and fear have the opposite effect on risk preference. In Lerner et al.'s (2003) study, participants read either a news story about celebrations of the attacks by people in Arab countries to evoke anger, or a news story about anthrax mail threat and bioterrorism to evoke fear. Anger prompted people, especially males, to seek more risks in decision making and strongly supported the vengeful deportation policy. The effect of anger on risk preference in policymaking is also seen in the Authorization for Use of Military Force passed in the United States Congress on September 14, 2001, in the wake of 9/11 terrorist attack. The only representative who voted against the Authorization was the female Congresswoman Barbara Lee (Congressional Record, 2001). By contrast, fear prompted people to take more precaution, make less risky decisions, and recommend the conciliatory contact policy in Lerner et al.'s study. For educational leaders, fear tends to hold them back and make risk-averse decisions. For instance, the superintendent decided to bow to the pressure from the parents and teachers who were angry after the district proposed to divert funds from highperforming students to low-performing students (Zirkel \& Pollack, 2016).

Social preference. Social emotions, as the name implies, influence decision-makers' social preference. Some emotions (e.g., empathy, compassion, awe, gratitude, and guilt) increase social preference, prompting prosocial behaviors such as being cooperative and helping others; other emotions (e.g., anger, anxiety, disgust, envy, and pride) decrease social preference, leading to anti-social behaviors such as interrupting others, using threatening, bullying, and insulting 
tactics, being deceitful and evasive, as well as being verbally and physically aggressive (Blasé \& Blasé, 2002).

Both empathy and compassion, under certain circumstances, increase our social preference in decision making. Empathy is experienced when we consciously put ourselves into the mind of another individual and imagine what that person is feeling and thinking (Decety \& Cowell, 2015). If empathy is about feeling with the other, then compassion is about feeling for the other. Compassion "is characterized by feelings of warmth, concern and care for the other, as well as a strong motivation to improve the other's wellbeing" (Singer \& Klimecki, 2014, p. 875). Being attentive to others and being motivated to care for others - as the core elements of caring leadership — are grounded in empathy and compassion (Louis, Murphy, \& Smylie, 2018). Indeed, empathy and compassion motivate us to be altruistic (Mathur, Harada, Lipke, \& Chiao, 2010). In organizations, altruistic behavior is deemed as organizational citizenship behavior (Organ, 1990). The teachers who demonstrated organizational citizenship behavior were described by Hargreaves (1998) with emotion-laden terms, "emotional, passionate beings who fill their work and their classes with pleasure, creativity, challenge and joy" (p. 559). However, empathy does not motivate our prosocial behavior towards all people in a universal way. Rather, empathy biases people's social preference toward ingroups - those who are like us in the same social categorization such as race, gender, religion, and socioeconomic status (Roccas \& Brewer, 2002). There is consistent evidence denoting that human brains have reduced neural responses to the pain being inflicted on ethnic outgroup members (Hein et al., 2010; Lamm \& Majdandžić, 2014). In fact, empathy sometimes drives aggression, malice, and dehumanization towards outgroups. This dark side of empathy is similar to the effect of disgust on social preference. Disgust is the marker of stigmatizing, stereotyping, and dehumanizing outgroups, thereby biasing 
decision-makers' social preference towards ingroups (Harris \& Fiske, 2006). Thus, the effect of empathy and disgust on people's social preference is context-dependent on the decision-makers' social identity: Who is Us? Who is Them?

Awe and gratitude are self-transcendent emotions - the emotions that "function to bind individuals together in social relationships by promoting cooperation and group stability" (Stellar et al., 2017, p. 201). Awe is an emotion evoked by something vast (Keltner \& Haidt, 2003). We experience awe when we stand at the mountaintop with a panoramic view, when we study a masterpiece of art and science, and when we encounter a charismatic leader. The awe-inspiring experience has a self-diminishing effect (Shiota, Keltner, \& Mossman, 2007), and is associated with increased moral decision making, helping others, generosity, and decreased entitlement (Piff, Dietze, Feinberg, Stancato, \& Keltner, 2015). Regarding gratitude, people who feel grateful are less inclined to be over-confident and narcissistic (McCullough, Kilpatrick, Emmons, \& Larson, 2001), but more altruistic to others (Kini, Wang, McInnis, \& Brown, 2016). Moreover, expressing gratitude to others makes our social partners feel valued and motivated, preventing them from emotional exhaustion which is one of the sources of teacher burnout (Grant \& Gino, 2010; Schwab \& Iwanicki, 1982).

Anger is a visceral emotion experienced when we feel that others are responsible for our unpleasant state (Siemer, Mauss, \& Gross, 2007). When we are angry, we tend to be more aggressive towards others (Manuck et al., 1999). In welfare policy making, when decisionmakers felt angry, they allocated fewer resources to welfare recipients; whereas when decisionmakers felt sad, they allocated more resources (Small \& Lerner, 2008). Moreover, when we are angry, we are more likely to evaluate others' ideas negatively (Wiltermuth \& Tiedens, 2011), because the brain area amygdala has a selective role in emotional arousal, especially for the 
negative stimuli (Bernston, Bechara, Damasio, Tranel, \& Cacioppo, 2007). However, anger does not always have negative consequences. Humans have a natural preference for justice, and injustice stokes anger in us (Decety \& Yoder, 2017). When we are treated unfairly, anger prompts us to reject unfairness (Sanfey, Rilling, Aronson, Nystrom, \& Cohen, 2003). When we see others being treated unfairly (e.g., being deprived of their rights or getting less than they deserve), our natural preference for justice is violated, triggering moral outrage which motivates us to right the wrong, object to the people and policies that engender injustices, and altruistically punish wrongdoers who violate moral norms (Decety \& Cowell, 2015). In leadership practice, leaders' anger should not be categorically suppressed. Under certain circumstances, leaders' anger expression was appropriate, even beneficial. For instance, a leader's anger expression in response to followers' integrity-based violations was positively associated with the followers' perceptions of leadership effectiveness (Wang, Restubog, \& van Kleef, 2018).

Time preference. Time preference refers to people's preference for a smaller immediate reward here and now or a larger delayed reward there and later. People tend to value immediate reward highly and discount the long-term rewards, preferring short-sighted outcomes at the expense of better outcomes in the long run. This tendency is called the here-and-now bias (i.e., wanting instant gratification right now rather than a larger gain later on). Sadness increases the here-and-now preference in decision making. People who felt sad have a myopic focus on the present, assigning more value to the immediate reward but discounting the value of the same reward delivered in the future (Keltner, Oatley, \& Jenkins, 2014).

On the contrary, pride and gratitude enable decision-makers to prefer reward delivered later. Pride is elicited when individuals feel that the self is attributed to having brought positive outcomes (Lerner \& Keltner, 2000). Pride thus has a motivational function: prideful individuals 
are willing to shoulder short-term hedonic cost in order to persevere and achieve long-term goals (Williams \& DeSteno, 2008). Gratitude is an emotion aroused when we affirm goodness in the world (e.g., help, gifts, and benefits we have received), and when we recognize the source of this goodness does not come from ourselves but from the goodwill of others, or even higher powers if we are religious (Emmons \& McCullough, 2004). In decision making, gratitude enables people to assign more value to long-term gains in social interactions (e.g., social capital) and less value to short-term costs (Dickens \& DeSteno, 2016).

Notably, it takes self-control to resist the temptation of immediate gratification and wait for a larger reward delivered later. Self-control demands enormous cognitive effort which is a limited resource (Barrett, 2017). For this reason, anything that drains decision makers' cognitive resources - from being emotionally exhausted to mentally spent—undermines leaders' willpower and self-control, diminishing their effort to focus on the long-term gains and thus leading to myopic decisions (Greene et al., 2004). Using cognitive resources for one decision means that they may not be available for other decisions. This cognitive cost must be taken into account as educational leaders attempt to optimize their decision making.

To sum up, emotions have a pervasive, predictable role at the moment of decision making. Specifically, emotions play a predictable role in educational leaders' risk, social, and time preferences, as the leaders assign a subjective value to different options over the decisionmaking processes. Therefore, evoking different emotions at the moment of decision making can yield different decision outcomes. As such, changing emotions can gently nudge the leaders to different choices. 


\section{Proposition 3: Individual differences and organizational contexts have a bearing on leaders' emotions and decision making.}

Prior to decision making, educational leaders' individual traits (e.g., trait affect and power) and organizational contexts (e.g., organizational justice and emotional contagion) could yield different emotions and decision outcomes. Below I elucidate how each factor holds sway over educational leaders' emotions and decisions.

Trait affect \& emotions. Trait affect, as a personality trait of an individual's general emotional tendencies (Watson et al., 1988), influences decision making. Those with trait positive affect have a predisposition to experience positive emotions (e.g., being optimistic, resilient, enthusiastic, and energetic) across time and situations. People with positive trait affect are more willing to take risks in decision making (Mittal \& Ross, 1998). By contrast, people with negative trait affect experience negative emotions consistently (e.g., being angry, fearful, anxious, and nervous; Watson \& Clark, 1984). In their aptly titled article "If You Feel Bad, It's Unfair”, Barsky and Kaplan (2007) found that people with trait negative affect were more likely than others to perceive organizational injustice (i.e., the unfairness in organizations) which could trigger emotions and influences people's decisions, a point I will return to shortly.

Power \& emotions. Leaders vary in their implicit power motivation — an unconscious motivation to derive pleasure from having control over the behaviors and circumstances of others by reward- and punishment-related resources (e.g., deliver rewards such as job promotion or administer punishment such as job termination; Fiske, 1993; McClelland \& Boyatzis, 1982). Paradoxically, to acquire power, people need to be emotionally resonant (Boyatzis et al., 2012) and express social emotions — such as empathy and compassion—by exhibiting eye contact while speaking and being agreeable. However, once people assume positions of power, they tend 
to have diminished empathy and compassion, demonstrating anti-social behaviors such as being aggressive, coercive, impulsive, and deceptive. This psychological effect of power is called the "power paradox": the social and emotional skills that are most important to leadership are the very skills that deteriorate once people have power (Keltner, 2017). The feeling of power changes how human brains respond to others emotionally in a way that is similar to the patients having a brain damage in the orbitofrontal cortex - the brain area that is crucial for empathy and decision making (Hogeveen, Inzlicht, \& Obhi, 2014). The patients with the brain damage in this area tend to make cold-hearted decisions such as highly utilitarian decisions to maximize the benefits for the group (e.g., being willing to sacrifice one family member to save five strangers), have diminished ability to feel empathy, guilt, and regret (Bechara, 2004), and judge others' emotions less accurately (Galinsky, Mage, Ines, \& Gruenfel, 2006). The high-power decisionmakers' deteriorating emotional skills explain why they demonstrate anti-social behaviors, include turning a blind eye to the suffering and distress of others (van Kleef et al., 2008), as well as being verbally and physically aggressive (Koski et al., 2015). It is not uncommon to see some educational leaders' abuse of power and mistreatment of teachers (Blasé \& Blasé, 2002). Worse, those who have an inflated egotistical perception of their power exhibit egocentric advice discounting: overweighing their own opinions, but discounting advice from others; accordingly, people in positions of power are more likely to rely on stereotypes when judging other people in social settings (Fiske, 1993).

Organizational contexts \& emotions. Mindful of the social function of emotions (Keltner \& Haidt, 1999), in addition to a leader's individual differences in emotions, I situate educational leaders' emotions in organizational contexts. In schools, emotions are aroused, expressed (or suppressed), spread, and interpreted in the social system of organizations. People 
in some schools might experience collective enthusiasm, awe, and gratitude which increase their social preference, leading to increased cooperation within organizations. People in other schools might share the emotions of fear, anger, and disgust which decrease their social preference and the resultant inhibited cooperation. Here I highlight two factors that influence educational leaders' emotions: organizational justice and emotional contagion.

Organizational justice \& emotions. Organizational justice refers to subjective perceptions of fairness in organizations (Colquitt, Conlon, Wesson, Porter, \& Ng, 2011). On the one hand, being treated fairly is positively associated with self-reported happiness, as attested by brain imaging evidence indicating the activation of the dopaminergic reward system which makes people feel gratified (Tabibnia, Satpute, \& Lieberman, 2008). On the other hand, organizational injustice takes in three forms: (1) procedural injustice - the unfairness of the procedures used to allocate organizational resources (e.g., hiring people based on nepotism rather than merits); (2) distributive injustice - the unfairness of outcome distribution (e.g., schools disproportionately allocate resources to high-performing students; Zirkel \& Pollack, 2016); and (3) interactional injustice — treating people unfairly without dignity and respect (e.g., school principals belittle and publicly criticize teachers; Blasé \& Blasé, 2002). Organizational injustice is rooted in emotional arousing and processing, thereby influencing decision making. Specifically, being treated unfairly, people feel angry and resentful, which leads to aggressive behavior and even retaliation in organizations (Skarlicki \& Folger, 1997). Moreover, as people’s perception of fairness is usually biased towards themselves, those who benefit from injustices in an organization tend to resent and resist organizational changes that attempt to rid the injustices. This explains why social justice-driven school leaders reported the resistance they faced took an emotional toll on them, and felt frustrated, defeated, and discouraged (Theoharis, 2007). These 
emotions, as noted previously in Proposition 2, have a predictable effect on educational leaders' risk, social, and time preferences in their decision making.

Emotional contagion. In organizations, people express their emotional experience to others through verbal and nonverbal communication. Such emotion expression becomes social stimuli, triggering others' emotions (Barrett, 2017). For this reason, emotions are contagious in organizations. The unconscious transfer of emotions among people is considered as emotional contagion (Barsade, 2002). Over time, people's experience of emotions become similar, and thus emotions tend to converge among people in organizations, creating an emotional echo chamber (Anderson, Keltner, \& John, 2003). To that end, school leaders' emotions impact others' emotions and decisions; others' emotions influence the leaders' emotions and decisions as well. Regarding emotional contagion from leaders to followers, it was found that leaders' positive emotions, in comparison to negative emotions, were associated with the group's positive emotions, greater cooperation, and less conflict within the group (Bono \& Ilies, 2006). Emotional contagion from followers is related to their perceptions of the leaders' charisma, trust in organizations, organizational culture, organizational justice, and the group's organizational citizenship behavior (Barsky \& Kaplan, 2007; Dasborough, Ashkanasy, Tee, \& Tse, 2009; Johnson, 2008). From the perspective of emotional contagion, teacher burnout is contagious, because teachers' emotions — such as feeling demotivated and emotionally exhausted — can be transferred unconsciously within schools (Schwab \& Iwanicki, 1982). Suffice it to say, given the contagious nature, emotions are social assets in organizations. They are more appropriately examined at both individual and group level in organizational contexts. Thanks to the communication and motivation function, emotions forge social bonds in organizations. Positive emotions (e.g., awe, compassion, gratitude, and passion) can create and sustain a caring, 
nurturing organizational culture through shaping rituals, norms, perceptions, and expectations; toxic emotions (e.g., anger, fear, anxiety, disgust, and jealousy) can rip apart and tear down an organization. Optimizing leaders' decision-making process entails the leaders to attend to both their own and team members' emotions.

Briefly stated, prior to decision making, educational leaders' individual differences (e.g., trait affect and power) and organizational contexts (e.g., organizational justice and emotional contagion) influence their emotions which hold sway over the leaders' subjective valuation of options in terms of risk, social, and time preferences over the decision-making processes. As a result, the variations in the aforementioned individual differences and organizational contexts could yield different emotions and different decisions.

\section{Proposition 4: Post-decision behavioral responses trigger more emotions which, in turn, influence the next cycle of decision-making process.}

Leaders' behavioral responses, derived from their decision making, function as social stimuli and trigger more emotions which influence the next cycle of decision-making process. Thus, behaviors yield emotions, and emotions yield behaviors, and so on and so forth. Consider the example documented in a study on school reform (Datnow \& Castellano, 2001). The school leader enthusiastically supported a new curriculum, and $80 \%$ of the teachers voted in favor of adopting the curriculum. After the decision, some teachers felt valued as they implemented the curriculum, thereby committing themselves to collaboration and collegiality over the implementation process; whereas other teachers felt pressured to adopt the curriculum. Here positive emotions, as noted earlier, increased decision makers' risk preference; therefore, those who were enthusiastic, optimistic, and excited were more willing to take risks than those who had neutral emotions (Mittal \& Ross, 1998). The risk-taking behavior (e.g., adopting the new 
curriculum) then triggered more emotions (e.g., felt valued or pressured) which influenced the next cycle of decision-making process.

In addition to the predictable effect of emotions on decision making and the subsequent behavior, there are three unique post-decision emotions (regret, guilt, and shame) holding sway over decision making. Regret is a complex, counterfactual emotion (Zeelenberg, van Dijk, \& Manstead, 1998). When the alternative option produces better outcomes than the one we select, we feel regretful (Tsiros, 1998). Regret is thus viewed as a consequence of decision making, as we feel responsible for the decision. Further, regret can also be viewed as an antecedent to decision making in the form of anticipated regret, thereby operating as the integral emotion (i.e., the emotion aroused by the decisions at hand). Regret lowers risk preference, prompting decision-makers to be risk-averse and cautious (Coricelli et al., 2005).

Guilt, as a negative self-conscious emotion, is evoked by the infliction of harm, loss, or distress on a social partner (Tangney, Stuewig, Mashek, \& Hastings, 2011). Feeling guilty over hurting our social partners or letting down our social partners' expectation increases our social preference for others. To maintain and strengthen the social relationships, we are more likely to empathize with others (Tangney, Stuewig, \& Mashek, 2007). For instance, Mawhinney and Rinke (2017) reported that the teachers who taught in urban school districts felt guilty, which propelled them to advocate for their students.

Shame, as another negative self-conscious emotion, is evoked when we feel we are responsible for unpleasant outcomes that are incompatible with our ideal self (Tangney, Wagner, Fletcher, \& Gramzow, 1992). Shame-laden individuals disapprove of themselves and lose confidence in their own decision making; therefore, they are receptive to inconsistent information that counters their own preference in decision making (Agrawal et al., 2013). 
Above, the organizing framework illustrates and outlines the role of emotions in educational leaders' decision making. Extant literature in multiple disciplines has lent strong support that decisions are the outcomes of emotion-cognition interactions. Emotions are "(1) inputs to decisions through the valuation of their components, (2) accompaniments to the process of decision making, and (3) outputs of the process that include feelings about the actions chosen as well as an overall feeling of satisfaction or dissatisfaction about the choices that have been made" (Thagard, 2012, p. 120). As a result, emotions are not simply a disruptive force, hijacking decision-makers' cognition, reasoning, and rationality in decision making. Instead, emotions are essential prior to, at the moment of, and after decision making.

\section{Discussion}

Building on prior work on emotions in educational leaders' decision making, this article proposes an organizing framework after examining the converging evidence of the role of emotions and decision making from multiple disciplines. The framework inevitably simplifies a complicated decision-making process in order to be applicable for educational leadership researchers and practitioners. In fact, that is exactly what frameworks do. The framework does not work like a Global Position System (GPS) that provides specific directions for leaders at every turn of their complex decision-making processes. Rather, a better way is to use this framework as a compass - the one that provides a general direction, because emotions have a predictable effect on risk, social, and time preferences. For instance, if educational leaders feel angry, they are likely to be risk-seeking in decision making; if they feel fearful, they are likely to be risk-averse. By illustrating how emotions play a predictable role prior to, at the moment of, and after decision making, this framework bolsters the recently proposed affective paradigm for educational leadership theory and practice (James et al., 2018). In addition to data-driven 
decision making, the proposed framework widens the scope of decision-making approaches by situating educational leaders in a context that emotions are aroused by incomplete data and uncertainty in organizations. In this section, I discuss the implications of the proposed framework for future research and school leadership preparation and training.

\section{Implications for Future Research}

The proposed framework calls for an intensified scholarly inquiry into educational leaders' emotions and decision making. Instead of pitting emotions against cognition, the telling evidence from multiple disciplines suggests that emotions serve as an essential component in optimal decision making, because they influence the subjective value of options in terms of risk, social, and time preferences. Using a data-driven approach, educational leaders can reduce the unpredictability and uncertainty of the options in decision making. However, decisions sometimes are made without accurate data available. Under such circumstances, educational leaders need to make risky decisions, from barely conscious ones (e.g., favoring ingroup members in hiring) to carefully deliberated ones about initiating and catalyzing organizational changes to serve the best interest of students. Organizational change is highly emotion-eliciting (Elfenbein, 2007). Over the process of organizational change, educational leaders might experience a wide range of different emotions - from anger at themselves and others to shame, agony, sadness, powerlessness, depression, fear, frustration, and happiness. Given the pervasive, predictable role of emotions in decision making, inducing different emotions can potentially change decisions. Therefore, with many high-stakes decisions made by educational leaders, emotions can have a powerful impact on schools. When and how do leaders create emotional experiences that motivate teachers, students, and communities to galvanize organizational changes and fulfill the schools' vision? How skillful is a leader at inspiring hope, cognitively and 
emotionally framing the risk involved in an organizational change into a motivating force that transforms the organization? How to ensure organizational justice, so that teachers feel they are valued, their work is appreciated, and feel motivated to seek, provide, and share advice and ideas in schools? The answers to these questions are particularly important in low-performing schools that might be overflowing with negative emotions of anger, frustration, aggression, anxiety, and fear. It is thus a fruitful area for future inquiry to examine educational leaders' decision making in highly contextualized, emotion-evoking organizational settings.

Another implication of the proposed organizing framework is that data-driven or emotion-laden decision making should not be an either-or question but a both-and question. Data-driven decision making is appealing to school leaders, as data can be used to assess teacher instruction and student learning. Yet such a decision-making approach has its limitations. When data are offered unskillfully without appropriate framing, or at the wrong timing when certain emotions (e.g., anger and pride) run high, and when leaders feel emotionally drained, the data could be readily dismissed by the leaders. Moreover, the data themselves arouse emotions as leaders examine and interpret them. Take the data on school safety as an example. In 2018, there were 24 school shootings that took 35 lives and injured 79 people in the United States (Education Week, 2018). The school shootings elicited terror and fear which narrowed decision makers' attention breadth and enabled their cognitive system to focus on the salient option (e.g., the proposal to fund more police officers in schools; Haslett, 2019). Fear also makes decision makers risk-averse. School leaders are likely to make decisions about school safety out of an abundance of caution, as no leader wants to appear soft on school safety, regardless of the data. Another limitation of data-driven decision making is that it falls short of guiding school leaders' decision making when they are confronted with competing interests. What if there is a tension between 
leaders' self-interest (e.g., to advance the leader's career as fast as possible) and the collective group interest of the teachers and students (e.g., additional time and resources are needed to achieve quality teaching and learning)? Also, imagine a school leader who has finite resources that can be allocated to meet the learning needs of a fixed number of students. Should the leader allocate the resources to low-performing students whose academic achievement might not yield a substantial improvement in the school rating in state accountability system in the short term, or to those students who have a better chance of passing the state assessment and giving school rating a solid grounding at the end of school year (Booher-Jennings, 2005)? When school leaders supervise special education programs and services, should the leaders allocate the finite resources to serve the best interests of one student or the best interests of all students (Frick, Faircloth, \& Little, 2013)? In the cases in which students, teachers, and leaders have competing interests, data-driven decision making appears to fail to provide clear, practical guidance for school leaders regarding which option should take precedence in decision making.

In leadership practice, sometimes educational leaders go with their gut and follow their heart, which reflects their instincts, gut feelings, and emotions. However, when leaders allow their emotions to go unchecked without being analytical and deliberate, they may become too impulsive, too risk-averse or risk-seeking in decision making. Yet this by no means suggests that emotions should be entirely suppressed to promote sound decisions, because emotions serve as the important inputs in the decision-making processes (Pfister \& Böhm, 2008). Being too datadriven, leaders may become cold-hearted and calculating without compassion for others, thereby having a deleterious effect on motivating others. Still, there are times when leaders must use data, engage in analytical thinking without strong emotions kicking in. The real question is how to strike a balance. When should educational leaders make rational, deliberate, disinterested 
decisions not unduly influenced by emotional appeals? When to make an impassioned plea to motivate people by arousing their emotions? Searching for answers to these questions could turn out to be another fertile research line for future inquiry in the field of educational leadership.

\section{Implications for School Leadership Preparation and Training}

The proposed framework also calls for an intensified training of emotions in school leadership preparation programs and professional development. Educational leadership literature has already suggested the need for emotional support for social justice-driven school leaders (Theoharis, 2007). To ensure justice in schools and to optimize leaders' decision making, it is important to train educational leaders to be aware of their own emotions, regulate emotions, express emotions appropriately, and recognize others' emotions. Not all negative emotions have negative consequences. Anger, particularly moral outrage, motivates leaders to ensure fairness and organizational justice in their decision making. Also, not all positive emotions have positive consequences. Empathy, for example, enables leaders to unconsciously favor ingroups and discriminate outgroups (Lamm \& Majdandžić, 2014). The educational leaders' emotion training, therefore, should include emotion self-awareness, emotion regulation to keep undesirable emotions at bay, and appropriate emotion expression — both verbal and nonverbal— to be emotionally authentic and resonant with others in schools and communities. Leaders need not remain emotionless or always hide true feelings, but display the right emotions at the right time. Although all humans experience emotions, the frequency and intensity of emotional experience might differ from person to person. Some leaders are more prone to be decisive and are more comfortable with risks in decision making than others. Extraverted and agreeable leaders have a predisposed stance on social preference. To prepare effective educational leaders, it is also necessary that they are trained to assess which emotions they are particularly prone to feel, and 
are equipped with the techniques to minimize (or maximize) their emotional experience and regulate their emotions as needed.

\section{Conclusion}

This article proposes an organizing framework of educational leaders' emotions in decision making. Endowed with power, leaders, compared with others, make decisions that have higher stakes and more far-reaching consequences at both individual and organizational levels. In the organizing framework, Proposition 1 (the emotion-cognition interactions) is grounded in human brains' structure and function which indicate that decisions are the outcomes of emotioncognition interactions. Emotions are not the very antithesis of cognition which enables educational leaders' rational reasoning in decision making. As Frith and Frith (2006) noted, "when deciding what to do, we are not totally 'rational' in our choice of action; our choice is colored by emotions" (p. 533). This view suggests the need for an extended scope of leaders' decision making that takes into account the role of emotions in decision making. To do so, it is important to go beyond the sole focus on leaders' cognitive capacity to make decisions, such as data-driven, evidence-based decision making that derives from rational choice theory and utilitarianism. Moreover, Proposition 2, 3, and 4 describe the role of emotions prior to, at the moment of, and after decision making. Given the predictable effect of emotions on decision making, evoking different emotions can nudge leaders to different decision outcomes. To that end, the organizing framework paves the way for future research and school leadership training on how to capitalize on emotions to make wise decisions at both individual and organizational levels. 


\section{References}

Agrawal, N., Han, D., \& Dubachek, A. (2013). Emotional agency appraisals influence responses to preference inconsistent information. Organizational Behavior and Human Decision Processes, 120(1), 87-97.

Anderson, C., Keltner, D., \& John, O. P. (2003). Emotional convergence between people over time. Journal of Personality and Social Psychology, 84(5), 1054-1068.

Bandura, A. (1997). Self-efficacy: The exercise of control. New York: W. H. Freeman.

Barrett, L. F. (2017). How emotions are made: The secret life of the brain. New York, NY: Houghton Mifflin Harcourt.

Barsade, S. G. (2002). The ripple effect: Emotional contagion and its influence on group members. Administration Science Quarterly, 47(4), 644-675.

Barsky, A., \& Kaplan, S. A. (2007). If you feel bad, it's unfair: A quantitative synthesis of affect and organizational justice perceptions. Journal of Applied Psychology, 92(1), 286-295.

Bechara, A. (2004). The role of emotion in decision-making: Evidence from neurological patients with orbitofrontal damage. Brian and Cognition, 55(1), 30-40.

Bechara, A., Tranel, D., Damasio, H., Adolphs, R., Rockland, C., \& Damasio, A. R. (1995). Double dissociation of conditioning and declarative knowledge relative to the amygdala and hippocampus in humans. Science, 269(5227), 1115-1118.

Berkovich, I., \& Ori, E. (2015). Educational leaders and emotions: An international review of empirical evidence 1992-2012. Review of Educational Research, 85(1), 129-167.

Berkovich, I., \& Ori, E. (2017). Emotional reframing as a mediator of the relationships between transformational school leadership and teachers' motivation and commitment. Journal of Educational Administration, 55(5), 450-468. 
Bernston, G. G., Bechara, A., Damasio, H., Tranel, D., \& Cacioppo, J. T. (2007). Amygdala contribution to selective dimensions of emotion. Social Cognitive Affective Neuroscience, 2(2), 123-129.

Blasé, J., \& Blasé, J. (2002). The dark side of leadership: Teacher perspective of principal mistreatment. Educational Administration Quarterly, 38(5), 671-727.

Bono, J. E., \& Ilies, R. (2006). Charisma, positive emotions and mood contagion. The Leadership Quarterly, 17(4), 317-334.

Booher-Jennings, J. (2005). Below the bubble: "Educational triage" and the Texas accountability system. American Educational Research Journal, 42(2), 231-268.

Boyatzis, R. E., Passarelli, A. M., Koenig, K., Lowe, M., Matthew, B., Stoller, J. K., \& Phillips, M. (2012). Examination of the neural substrates activated in memories of experiences with resonant and dissonant leaders. The Leadership Quarterly, 23(2), 259-272.

Colquitt, J. A., Conlon, D. E., Wesson, M. J., Porter, C., \& Ng, K. Y. (2011). Justice at the millennium: A meta-analytic review of 25 years of organizational justice research. Journal of Applied Psychology, 86(3), 425-445.

Congressional Record. (2001). Authorization for Use of Military Force. Retrieved from https://www.congress.gov/bill/107th-congress/senate-joint-resolution/23

Cooper, J. M., \& Hutchinson, D. S. (Eds.). (1997). Plato: Complete works. Indianapolis, IN: Hackett Publishing.

Coricelli, G., Critchley, H. D., Joffily, M., O'Doherty, J. P., Sirigu, A., \& Dolan, R. J. (2005). Regret and its avoidance: A neuroimaging study of choice behavior. Nature Neuroscience, 8, 1255-1262. 
Damasio, A. R. (1994). Descartes' error: Emotion, reason, and the human brain. New York, NY: Putnam.

Damasio, A., \& Carvalho, G. B. (2013). The nature of feelings: Evolutionary and neurobiological origins. Nature Reviews Neuroscience, 14, 143-152.

Dasborough, M. T., Ashkanasy, N. M., Tee, Y. J., \& Tse, H. M. (2009). What goes around comes around: How meso-level negative emotional contagion can ultimately determine organizational attitudes toward leaders. The Leadership Quarterly, 20(4), 571-585.

Datnow, A., \& Castellano, M. E. (2001). Managing and guiding school reform: Leadership in success for all schools. Educational Administration Quarterly, 37(2), 219-249.

De Martino, B., Kumaran, D., Seymour, B., \& Dolan, R. J. (2006). Frames, biases, and rational decision-making in the human brain. Science, 313(5787), 684-687.

Decety, J., \& Cacioppo, S. (2012). The speed of morality: A high-density electrical neuroimaging study. Journal of Neurophysiology, 108(11), 3068-3072.

Decety, J., \& Cowell, J. M. (2015). Friends or foes: Is empathy necessary for moral behavior? Perspectives on Psychological Science, 9(5), 525-537.

Decety, J., \& Yoder, K. J. (2017). The emerging social neuroscience of justice motivation. Trends in Cognitive Sciences, 21(4), 6-14.

Dickens, L., \& DeSteno, D. (2016). The grateful are patient: Heightened daily gratitude is associated with attenuated temporal discounting. Emotion, 16(4), 421-425.

Education Week. (2018, December 19). The school shootings of 2018: What's behind the numbers. Retrieved from https://www.edweek.org/ew/section/multimedia/the-schoolshootings-of-2018-whats-behind.html

Ekman, P. (1993). Facial expression and emotion. American Psychologist, 48, 384-392. 
Ekman, P., \& Friesen, W. V. (1971). Constants across cultures in the face and emotion. Journal of Personality and Social Psychology, 17(2), 124-129.

Elfenbein, H. A. (2007). Emotion in organizations. Academy of Management Annals, 1(1), 315386.

Emmons, R., \& McCullough, M. (2004). The psychology of gratitude. New York, NY: Oxford University Press.

Fessler, D. M. T., Pillsworth, E. G., \& Flamson, T. J. (2004). Angry men and disgusted women: An evaluative approach to the influence of emotions on risk taking. Organizational Behavior and Human Decision Processes, 95, 107-123.

Figueroa, A. M. (2017). Speech or silence: Undocumented students' decisions to disclose or disguise their citizenship status in school. American Educational Research Journal, $54(3), 485-523$.

Fineman, S. (2003). Understanding emotion at work. Thousand Oaks, CA: Sage.

Finucane, M. L., Alhakami, A., Slovic, P., \& Johnson, S. M. (2000). The affect heuristic in judgments of risks and benefits. Journal of Behavioral Decision Making, 13, 1-17.

Fiske, S. T. (1993). Controlling other people: The impact of power o stereotyping. American Psychologist, 48(6), 621-628.

Fredrickson, B. L., \& Branigan, C. (2005). Positive emotions broaden the scope of attention and thought-action repertoires. Cognition and Emotion, 19(3), 313-332.

Frick, W. C., Faircloth, S. C., \& Little, K. S. (2013). Responding to the collective and individual "best interests of students": Revisiting the tension between administrative practice and ethical imperatives in special education leadership. Educational Administration Quarterly, 49(2), 207-242. 
Frith, C. D., \& Frith, U. (2006). The neural basis of mentalizing. Neuron, 50, 531-534.

Gazzaniga, M. (2011). Who's in charge? Free will and the science of the brain. NY, NY: HarperCollins.

Gazzaniga, M. S., Ivry, R. B., \& Mangun, G. R. (2013). Cognitive neuroscience: The biology of the mind $\left(4^{\text {th }} e d\right)$. New York, NY: W.W. Norton \& Company.

Galinsky, A. D., Magee, J. C., Inesi, M. E., \& Gruenfeld, D. H. (2006). Power and perspectives not taken. Psychological Science, 17, 1068-1074.

Gino, F., \& Schweitzer, M. (2008). Blinded by anger or feeling the love: How emotions influence advice taking. Journal of Applied Psychology, 93(5), 1165-1173.

Glimcher, P. W., \& Fehr, E. (2014). Neuroeconomics: Decision making and the brain. UK: Academic Press.

Grant, A. M., \& Gino, F. (2010). A little thanks goes a long way: Explaining why gratitude expressions motivate prosocial behavior. Journal of personality and social psychology, $98(6), 946-955$.

Greene, J. D., Nystrom, L. E., Engell, A. D., Darley, J. M., \& Cohen, J. D. (2004). The neural bases of cognitive conflict and control in moral judgment. Neuron, 44(2), 389-400.

Haidt, J. (2012). The righteous mind: Why good people are divided by politics and religion. New York, NY: Random House.

Hargreaves, A. (1998). The emotional practice of teaching. Teaching and Teacher Education, 14, 835-854.

Harris, L. T., \& Fiske, S. T. (2006). Dehumanizing the lowest of the low: Neuroimaging responses to extreme out-groups. Psychological Science, 17(10), 847-853. 
Haslett, C. (2019, March 5). Schools getting more police but at the expense of counselors, nurses: Report. ABC News. Retrieved from https://abcnews.go.com/Politics/studentscolor-students-disabilities-arrested-school-police-report/story?id=61454820

Hein, G., Silani, G., Preuschoff, K., Batson, C. D., \& Singer, T. (2010). Neural responses to ingroup and outgroup members' suffering predict individual differences in costly helping. Neuron, 68(1), 149-160.

Hogeveen, J., Inzlicht, M., \& Obhi, S. S. (2014). Power changes how the brain responds to others. Journal of Experimental Psychology: General, 143(2), 755-762.

Hoy, W. K. (1982). Recent developments in theory and research in educational administration. Educational Administration Quarterly, 18(3), 1-11.

James, C., Crawford, M., \& Oplatka, I. (2018). An affective paradigm for educational leadership theory and practice: Connecting affect, actions, power and influence. International Journal of Leadership in Education. doi: 10.1080/13603124.2018.1481536

Johnston, E., \& Olson, L. (2015). The feeling brain: The biology and psychology of emotions. New York, NY: W. W. Norton \& Company.

Johnson, S. K. (2008). I second that emotion: Effects of emotional contagion and affect at work on leader and follower outcomes. The Leadership Quarterly, 19(1), 1-19.

Kable, J. W., \& Glimcher, P. W. (2009). The neurobiology of decision: Consensus and controversy. Neuron, 63(6), 733-745.

Kahneman, D., \& Tversky, A. (1979). Prospect theory: An analysis of decision under risk. Econometrica, 47, 263-291.

Keltner, D. (2017). The power paradox: How we gain and lose influence. New York, NY: Penguin Books. 
Keltner, D., \& Haidt, J. (1999). Social functions of emotions at four levels of analysis. Cognition and Emotion, 13(5), 505-521.

Keltner, D., \& Haidt, J. (2003). Approaching awe, a moral, spiritual, and aesthetic emotion. Cognition and Emotion, 17(2), 297-314.

Keltner, D., Oatley, K., \& Jenkins, J. M. (2014). Understanding emotions. Hoboken, NJ: Wiley.

Kini, P., Wang, Y. J., McInnis, S., \& Brown, J. (2016). The effects of gratitude expression on neural activity. NeuroImage, 128, 1-10.

Lakomski, G., \& Evers, C. W. (2010). Passionate rationalism: The role of emotion in decisionmaking. Journal of Educational Administration, 48(4), 438-450.

Lamm, C., \& Majdandžić, J. (2014). The role of shared neural activations, mirror neurons, and morality in empathy-A critical comment. Neuroscience Research, 90, 15-24.

Leithwood, K., Steinbach, R., \& Jantzi, D. (2002). School leadership and teachers' motivation to implement accountability policies. Educational Administration Quarterly, 38(1), 94-119.

Lerner, J. S., Gonzalez, R. M., Small, D. A., \& Fischhoff, B. (2003). Effects of fear and anger on perceived risks of terrorism: A national field experiment. Psychological science, 14(2), 144-150.

Lerner, J. S. \& Keltner, D. (2000). Beyond valence. Toward a model of emotion-specific influences on judgment and choice. Cognition and Emotion, 14, 473-493.

Lerner, J. S., Li, Y., Valdesolo, P., \& Kassam, K. S. (2015). Emotion and decision making. Annual Review of Psychology, 66, 799-823.

Louis, K., Murphy, J., \& Smylie, M. (2018). Caring leadership in schools: Findings from exploratory analyses. Educational Administration Quarterly, 52(2), 310-348. 
MacLean, P. D. (1954). Studies on limbic system (visceral brain) and their bearing on psychosomatic problems. In E. Wittkower \& R. Cleghorn (Eds.), Recent Developments in Psychosomatic Medicine (pp. 101-125). London, UK: Pitman.

Manuck, S. B., Flory, J., Ferrell, R. E., dent, K. M., Mann, J. J., \& Muldoon, M. F. (1999). Aggression and anger-related traits associated with a polymorphism of the tryptophan hydroxylase gene. Biological Psychiatry, 45(5), 603-614.

Mathur, V. A., Harada, T., Lipke, T., \& Chiao, J. Y. (2010). Neural basis of extraordinary empathy and altruistic motivation. NeuroImage, 51(4), 1468-1475.

Mawhinney, L., \& Rinke, C. R. (2017). I just feel so guilty: The role of emotions in former urban teachers' career paths. Urban Education, 53(9), 1079-1101.

McCullough, M. E., Kilpatrick, S. D., Emmons, R. A., \& Larson, D. B. (2001). Is gratitude a moral affect? Psychological Bulletin, 127, 249-266.

McClelland, D. C., \& Boyatzis, R. E. (1982). Leadership motive pattern and long-term success in management. Journal of Applied psychology, 67(6), 737-743.

Mittal, V., \& Ross, W. T. (1998). The impact of positive and negative affect and issue framing on issue interpretation and risk taking. Organizational Behavior and Human Decision Processes, 76(3), 298-324.

Molenberghs, P., Prochilo, G., Steffens, N. K., Zacher, H., \& Haslam, S. A. (2017). The neuroscience of inspirational leadership: The importance of collective-oriented language and shared group membership. Journal of Management, 43(7), 2168-2194.

Öhman, A. (2005). The role of the amygdala in human fear: Automatic detection of threat. Psychoneuroendocrinology, 30(10), 953-958. 
Oplatka, I. (2009). The field of educational administration: An historical overview of scholarly attempts to recognise epistemological identities, meanings and boundaries from 1960s onwards. Journal of Educational Administration, 47(1), 8-35.

Organ, D. W. (1990). The motivational basis of organizational citizenship behavior. In L. L. Cummings \& B. M. Staw (Eds.), Research in organizational behavior (pp. 43-72). Greenwich, CT: JAI.

Pfister, H., \& Böhm, G. (2008). The multiplicity of emotions: A framework of emotional functions in decision making. Judgment and Decision Making, 3(1), 5-17.

Piff, P. K., Dietze, P., Feinberg, M., Stancato, D. M., \& Keltner, D. (2015). Awe, the small self, and prosocial behavior. Journal of Personality and Social Psychology, 108(6), 883-899.

Roccas, S., \& Brewer, M. B. (2002). Social identity complexity. Personality and Social Psychology Review, 6(2), 88 -106.

Sanfey, A. G., Rilling, J. K., Aronson, J. A., Nystrom, L. E. \& Cohen, J. D. (2003). The neural basis of economic decision-making in the Ultimatum Game. Science, 300(5626), 17551758.

Schultz, W., Dayan, P., \& Montague, P. R. (1997). A neural substrate of prediction and reward. Science, 275(5306), 1593-1599.

Schwab, R. L., \& Iwanicki, E. F. (1982). Perceived role conflict, role ambiguity, and teacher burnout. Educational Administration Quarterly, 18(1), 60-74.

Sergiovanni, T. J. (1992). Reflections on administrative theory and practice in schools. Educational Administration Quarterly, 28(3), 304-313. 
Sheffer, L., Loewen, P., Soroka, S., Walgrave, S., \& Sheafer, T. (2017). Nonrepresentative representatives: An experimental study of the decision making of elected politicians. American Political Science Review 112(2), 302-321.

Shiota, M. N., Keltner, D., \& Mossman, A. (2007). The nature of awe: Elicitors, appraisals, and effects on self-concept. Cognition \& Emotion, 21(5), 944-963.

Siemer, M., Mauss, I., \& Gross, J. J. (2007). Same situation-Different emotions: How appraisals shape our emotions. Emotion, 7(3), 592-600.

Singer, T., \& Klimecki, O. M. (2014). Empathy and compassion. Current Biology, 24(18), R875R878.

Skarlicki, D. P., \& Folger, R. (1997). Retaliation in the workplace: The roles of distributive, procedural, and interactional justice. Journal of Applied Psychology, 82(3), 434-443.

Small, D. A., \& Lerner, J. S. (2008). Emotional policy: Personal sadness and anger shape judgments about a welfare case. Political Psychology, 29(2), 149-168.

Smith, A. (1759/1976). The theory of moral sentiments. Indianapolis, IN: Liberty Classics.

Stellar, J. E., Gordon, A. M., Piff, P. K., Cordaro, D., Anderson, C. L., Bai, Y., ... Keltner, D. (2017). Self-transcendent emotions and their social functions: Compassion, gratitude, and awe bind us to others through prosociality. Emotion Review, 9(3), 200-207.

Tabibnia, G., Satpute, A. B., \& Lieberman, M. D. (2008). The sunny side of fairness preference for fairness activates reward circuitry (and disregarding unfairness activates self-control circuitry). Psychological Science, 19(4), 339-347.

Tangney, J. P., Stuewig, J., \& Mashek, D. J. (2007). Moral emotions and moral behavior. Annual Review of Psychology, 58, 345-372. 
Tangney, J. P., Stuewig, J., Mashek, D. J., \& Hastings, M. (2011). Assessing jail inmates’ proneness to shame and guilt: Feeling bad about the behavior or the self? Criminal Justice and Behavior, 38(7), 710-734.

Tangney, J. P., Wagner, P., Fletcher, C., \& Gramzow. R. (1992). Shamed into anger? The relation of shame and guilt to anger and self-reported aggression. Journal of Personality and Social Psychology, 62(4), 669-675.

Tarter, C. J., \& Hoy, W. K. (1998). Toward a contingency theory of decision making. Journal of Educational Administration, 36(3), 212-228.

Thagard, P. (2012). The brain and the meaning of life. Princeton, NJ: Princeton University Press. Theoharis, G. (2007). Social justice educational leaders and resistance: Toward a theory of social justice leadership. Educational Administration Quarterly, 43(2), 221-258.

Thoonen, E. E. J., Sleegers, P. J. C., Oort, F. J., Peetsma, T. T. D., \& Geijsel, F. P. (2011). How to improve teaching practices: The role of teacher motivation, organizational factors, and leadership practices. Educational Administration Quarterly, 47(3) 496-536.

Tsiros, M. (1998). Effect of regret on post-choice valuation: The case of more than two alternatives. Organizational Behavior and Human Decision Processes, 76, 48-69.

van Kleef, G. A., Oveis, C., van der Löwe, I., LouKogan, A., Goetz, J., \& Keltner, D. (2008). Power, distress, and compassion: Turning a blind eye to the suffering of others. Psychological Science, 19(12), 1315-1322.

Waldron, J. (2019, April 11). What goes on behind all the closed doors in politics? Education Week, 38(29). 18 
Wang, Y. (2018). The panorama of theoretical groundings of educational leadership research 2005-2014: A concept co-occurrence network analysis. Educational Administration Quarterly, 54(3), 327-365.

Wang, Y. (2019). Pulling at your heartstrings: Examining four leadership approaches from the neuroscience perspective. Educational Administration Quarterly, 55(2), 328-359.

Wang, Y., \& Bowers, A. J. (2016). Mapping the field of educational administration research: A journal citation network analysis. Journal of Educational Administration, 54(3), 242-269.

Wang, L., Restubog, S. L. D., \& van Kleef, B. S. L. A. (2018). Does anger expression help or harm leader effectiveness? The role of competence-based versus integrity-based violations and abusive supervision. Academy of Management Journal, 61(3), 1050-1072.

Watson, D., \& Clark, L. A. (1984). Negative affectivity: The disposition to experience negative emotional states. Psychological Bulletin, 96, 465-490.

Williams, L. A., \& DeSteno, D. (2008). Pride and perseverance: The motivational role of pride. Journal of Personality and Social Psychology, 94(6), 1007-1017.

Wiltermuth, S. S., \& Tiedens, L. Z. (2011). Incidental anger and the desire to evaluate. Organizational Behavior and Human Decision Processes, 116, 55-65.

Zeelenberg, M., van Dijk, W. W., \& Manstead, A. S. R. (1998). Reconsidering the relation between regret and responsibility. Organizational Behavior and Human Decision Processes, 74, 254-272.

Zirkel, S., \& Pollack, T. M. (2016). "Just let the worst students go": A critical case analysis of public discourse about race, merit, and worth. American Educational Research Journal, 53(6), 1522-1555. 


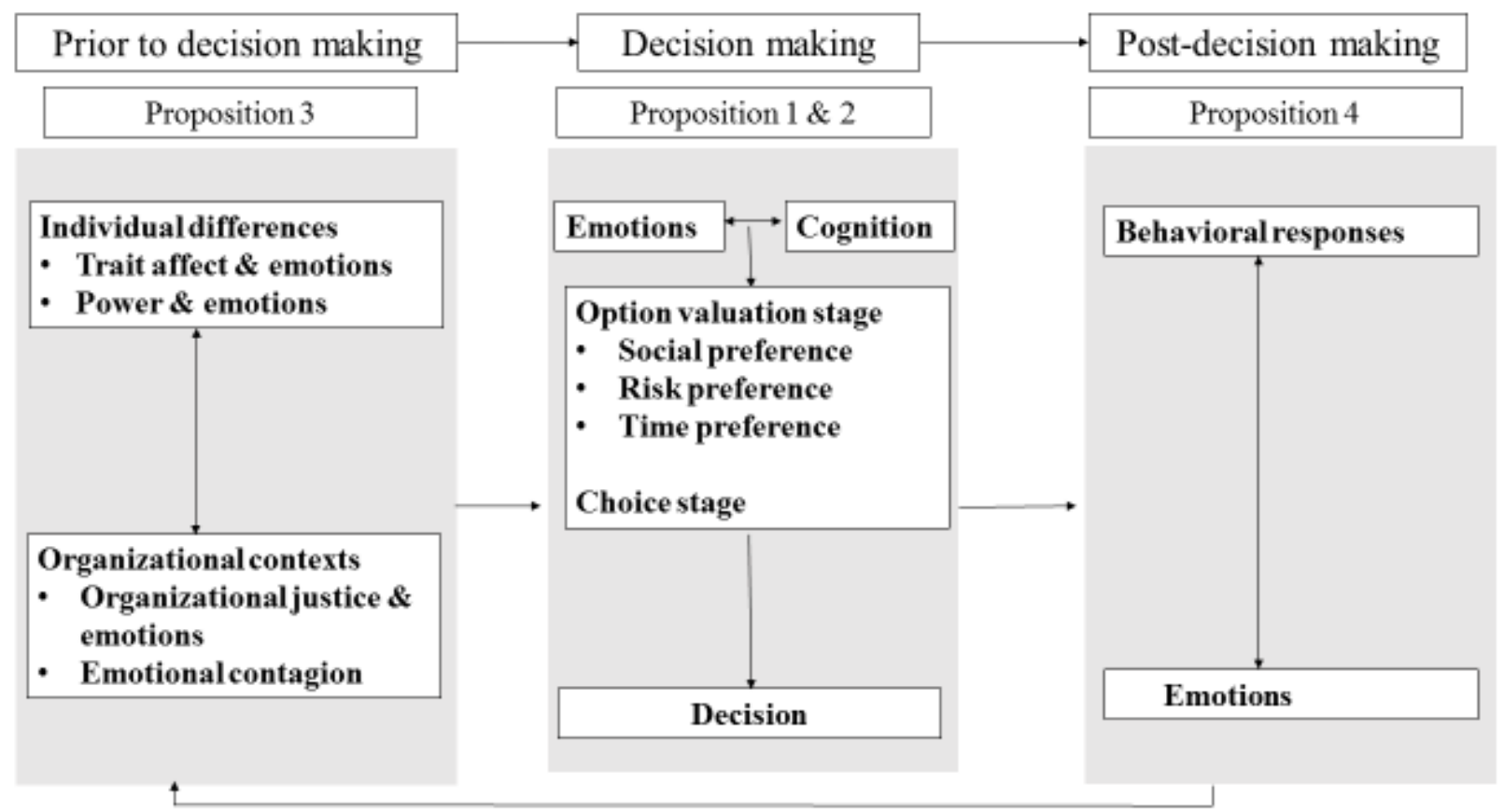

Figure 1 Organizing framework of educational leaders' emotions in decision making. 